\title{
Prevalence and incidence of multiple sclerosis in Catania, Sicily
}

\author{
A. Nicoletti, MD; M.L. Lo Bartolo, MD; S. Lo Fermo, MD; V. Cocuzza, MD; M.R. Panetta, MD; \\ C. Marletta, MD; M.R. Ciancio, MD; M.L. Cataldi, MD; F. Patti, MD; and A. Reggio, MD
}

\begin{abstract}
Article abstract-Objective: An epidemiologic survey was conducted to determine the prevalence and incidence of MS in the city of Catania, Sicily, Italy. Prevalence rate was calculated as point prevalence at January 1,1995, and incidence during 1974 to 1995. Methods: The authors studied the frequency of MS in the community of Catania in a population of 333,075 inhabitants according to the 1991 census. The primary sources for the case ascertainment were the neurologic and motor rehabilitation departments, the MS Center, the Italian MS Association, private neurologists, and family doctors. All patients who satisfied the Poser criteria for clinically definite MS, laboratory-supported definite MS, clinically probable MS, and laboratory-supported probable MS were considered prevalent and incident cases. Results: One hundred ninetyfive patients with MS who had had the onset of disease on prevalence day in a population of 333,075 inhabitants were detected. The prevalence rate was 58.5 per 100,000 (95\% CI 50.7 to 67.5). Prevalence was higher in women $(62.0 / 100,000)$ than in men (54.8/100,000). The age-specific prevalence showed a peak in the group aged 35 to $44(145.1 / 100,000)$. From 1975 to 1994, 170 subjects with MS had the clinical onset of the disease. The mean annual incidence was 2.3 per 100,000 (95\% CI 2.0 to 2.6). Age-specific incidence showed a peak in the group aged 25 to $34(6.32 / 100,000)$. Incidence for 5-year intervals increased from 1.3 during 1975 to 1979 to 3.9 during 1990 to 1994. Conclusions: These prevalence and incidence rates are close to those reported in other similar surveys carried out in Italy and southern Europe.
\end{abstract}

NEUROLOGY 2001;56:62-66

Many descriptive epidemiologic surveys have been carried out to determine the prevalence and incidence of MS during the last 20 years. Up to 1980, European countries from about 36 to $46^{\circ}$ north latitude showed prevalence rates ranging from 5 to 25 per 100,000, values lower than those reported for countries of central and northern Europe. More recent studies in Italy and in other countries of southern Europe, based on accurate case-finding procedures and classification of disease according to generally accepted diagnostic criteria, show that MS prevalence in this area is higher than had been believed. ${ }^{1}$ Estimated prevalence rates in continental Italy since 1980 range from 21.5 to 69.4 per $100,000,{ }^{2-3}$ excluding Sardinia, where prevalence reaches values of 143.9 per $100,000 .{ }^{4}$ Incidence studies around the world are more rare compared with prevalence studies. They show a variability in rates that in Europe range from 0.5 cases per 100,000 per year (Albania) to 4.0 (Gorski Kotar, Croatia). In Italy, incidence rates range from 2.1 (Valle d'Aosta) to 3.7 (Sardinia). ${ }^{5}$ Several studies have been carried out in Sicily during the last 20 years, reporting rates similar to those of central-northern Italy. ${ }^{1}$ In the city of Catania, the only survey was carried out in 1989, which reported a lower prevalence rate. ${ }^{6}$ The aim of our study was to revise the prevalence rates of MS in Catania and to evaluate the incidence trends during the last 20 years. This was the first survey carried out in such a large population ( $>300,000$ inhabitants) in southern Italy to estimate the incidence of MS.

Methods. Area of investigation. The survey was carried out in the city of Catania, the capital of the province in the eastern Sicily, whose geographic coordinates are $37^{\circ} 30$ north and $15^{\circ} 06$ east and which covers some $181 \mathrm{~km}^{2}$ (represented by a built-up center of some $39 \mathrm{~km}^{2}$ ), at a mean altitude of about 30 meters above sea level. Its official population in 1991 (date of the last census) $^{7}$ was 333,075 inhabitants, with 174,267 women and 158,808 men (figure 1). The climate is typically Mediterranean with a mean winter temperature of $9.5^{\circ} \mathrm{C}$, a mean summer temperature of $25.7^{\circ} \mathrm{C}$ (mean annual temperature of 17.6 ${ }^{\circ} \mathrm{C}$ ), and a mean annual rainfall of $543 \mathrm{~mm}$. According to census data, the population decreased from 400,048 in 1971 to 382,692 in 1981 and 333,075 in 1991, remaining stable from 1991 to 1995 (337,332 inhabitants). During the study period (1975 to 1994), there were not significant changes in sex and age structure of the population. In particular, during the study period, there was an internal migration flow from the city of Catania to the surrounding areas, but always in the province of Catania. The province of Catania covers $3,552 \mathrm{~km}^{2}$; and whereas the whole population of the province was stable over the period, about $1,000,000$ inhabitants, considering only the surrounding areas $(<15 \mathrm{~km}$ from the city), there was an increase from 84,200 inhabitants in 1971 to 146,882 in 1981 and to 185,140 in 1991. Immigration flow from other countries was low and stable over the period; in particular, in the last census of 1991, there were only 4,036 foreign residents

From the Institute of Neurological Science, University of Catania, Italy.

Received April 25, 2000. Accepted in final form August 24, 2000.

Address correspondence and reprint requests to Dr. A. Nicoletti, Istituto di Scienze Neurologiche, Università di Catania, Via Santa Sofia 78, 95125 Catania, Italy; e-mail: anicol@dimtel.nti.it

62 Copyright $\odot 2001$ by AAN Enterprises, Inc. 


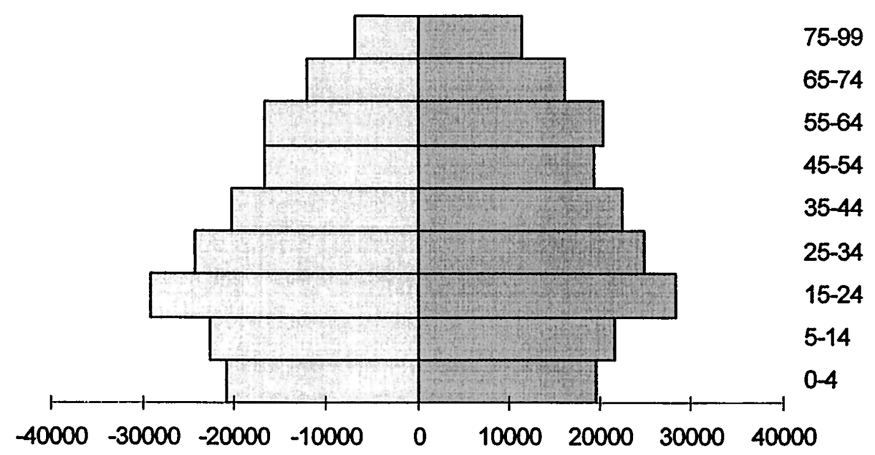

Figure 1. Age and sex distribution of the study population. Light gray bars = men; dark gray bars = women.

(1.2\% of the whole population), the most coming from Africa and Europe. On the basis of these data, the population could be considered ethnically stable in the city.

Case ascertainment. The primary sources for patient identification were the two neurologic departments of $\mathrm{Ca}$ tania (Neurologic Clinic of the University and Neurologic Division of Garibaldi Hospital) and the MS Center of the University of Catania. We examined all the clinical records starting from 1975. The same work was done with all the archives of pediatric departments, ophthalmologic clinics, centers for motor rehabilitation, centers of neuroradiology, and chronic care services present in the province of $\mathrm{Ca}$ tania. We requested a list of all the enrolled members of the Italian MS Association. Furthermore, we contacted all the family doctors and private neurologists in the province by letter, asking them to provide us with a list of patients with MS on their rosters. More than one article about the survey was published in the monthly Journal of the Medical Order of Catania. We also contacted by letter all the other neurologic departments in Sicily and other centers of MS in Italy. We reviewed all the archives starting from 1975 to 1999. Diagnoses of MS, demyelinating disease, optic neuritis, transverse myelitis, myelopathy, encephalomyelitis, Devic's disease, Schilder's disease, leukodystrophy, diplopia, and ataxia were sought.

All surviving potential patients with MS identified from these sources, except the patients with MS followed in our neurologic department and MS center, were called to undergo neurologic examination performed by trained neurologists of our team to confirm the diagnosis. When transportation was difficult, trained neurologists examined the potential patients with MS at home. For deceased patients, close relatives were interviewed.

Considering a mean length of time from onset to diagnosis of 5 years, we analyzed all the sources up to 1999 to detect the patients who had the clinical onset of disease before the prevalence day but fulfilled the diagnostic criteria adopted only after the prevalence day. We verified all the sources at least twice.

All existing records were manually reviewed. To minimize potential sources of error during the data collection, we selected a team of neurologic interns who spent at least 1 month at the MS center and who were previously trained for data abstraction. Information was collected on precoded forms created ad hoc and revised by a supervisor. Data were double entered into a computer using the Epi-Info version 6 package. ${ }^{8}$ Data were checked for consistency, and any errors were corrected.
Diagnostic criteria. In our study, we adopted the diagnostic criteria of Poser et al. ${ }^{9}$ All patients who satisfied these criteria for clinically definite MS (CDMS), laboratory-supported definite MS (LSDMS), clinically probable MS (CPMS), and laboratory-supported probable MS (LSPMS) were considered as prevalent and incident cases. The date of clinical onset was defined as the date when a patient first noticed a clear symptom of MS on the basis of the list of onset symptoms proposed by Poser in 1995. ${ }^{10}$ When available, the onset was established using objective data, or the history was obtained by interviewing patients and their close relatives. Patients with isolated retrobulbar optic neuritis were excluded from the study.

Prevalence was based on the number of patients who were living in the study area on January 1, 1995 (prevalence day) and had the clinical onset while living there (onset-adjusted prevalence rate). Crude prevalence rate was age adjusted to the world standard population ${ }^{11}$ and to the Italian population (national census 1991). ${ }^{7}$ To allow international comparison, we also calculated the prevalence rate considering only patients who fulfilled the diagnostic criteria on the prevalence day. Moreover, we calculated the onset-adjusted prevalence rate considering only the defined cases and not the probable ones.

Incidence was studied from 1975 to 1994 and was based on the year of the clinical onset (onset-adjusted incidence risk). Confidence intervals for estimates were calculated assuming a Poisson distribution. ${ }^{12}$

Results. At the end of the case ascertainment, 233 putative patients were identified. Based on the interview and neurologic examination, we excluded 15 patients who were not effectively resident at the onset of disease, 18 patients whose final diagnosis was other than MS, and 5 subjects whose clinical records did not allow us to make a probable or definite diagnosis of MS and who were not available for further evaluation.

Prevalence. On the prevalence day (January 1, 1995), we detected 195 patients with MS (87 men and 108 women) who were resident in the study area and who had experienced the clinical onset of the disease. According to Poser's diagnostic criteria, of these 195 prevalent patients, 173 were classified as CDMS, 3 as LSDMS, and 19 as CPMS.

The onset-adjusted prevalence rate (195 cases with onset before the prevalence day) was 58.5 per $100,000(95 \%$ CI 50.7 to 67.5). Age-adjusted prevalence to the Italian population (census 1991) was 55.4 per 100,000 and age adjusted to the world standard population 54.6. Overall, the prevalence was higher in women, 62.0 per 100,000 (95\% CI 51.1 to 75.1$)$, than in men, 54.8 per $100,000(95 \%$ CI 44.1 to 67.9 ).

Taking into account only the 176 cases classified as CDMS and LSDMS, the prevalence was 52.8 per 100,000 (95\% CI 39.8 to 68.6 ), 49.7 for men (95\% CI 36.9 to 65.5), and 55.7 for women (95\% CI 41.9 to 72.4 ).

Considering only patients with defined MS at the prevalence day (totally 144 cases), the prevalence was 43.2 per 100,000 (95\% CI 30.8 to 58.2), 45.3 for men (95\% CI 33 to 60.6), and 41.3 for women (95\% CI 29.5 to 56.2 ).

Analyzing the 195 prevalent patients, age-specific prevalence increased in the first groups of age, with a peak in the group aged 35 to 44 (145.1/100,000), and showed a steep decline in other groups, reaching a rate of 24.8 in the 
Table 1 Age- and sex-specific prevalence of MS in Catania, Italy

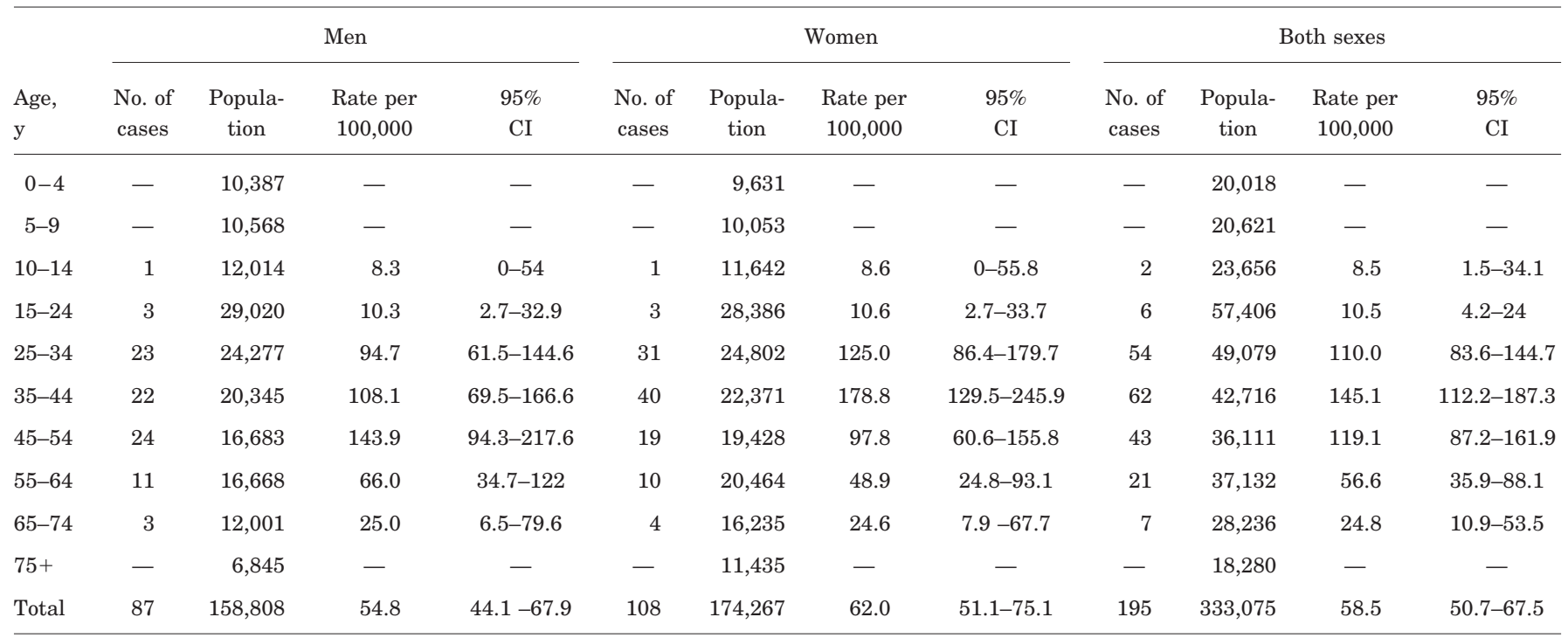

older age groups (65 to 74 years old). Table 1 shows ageand sex-specific prevalence rates per 100,000.

The mean age at onset was $29.6 \pm 9.6 \mathrm{SD}(29.8 \pm 9.9$ years for men and $29.5 \pm 9.3$ years for women) and ranged from 8 to 59 years. The average duration from onset to prevalence day was $11.3 \pm 8.6$ years $(11.8 \pm 8.3$ years for men and $10.8 \pm 8.8$ years for women), ranging from 1 to 48 years. The mean length of time between the clinical onset and the diagnosis was $5.0 \pm 5.2$ years $(4.5 \pm 5.3$ years for men and $5.3 \pm 5.0$ years for women).

Of 195 patients with MS at the prevalence day, 99 $(50.8 \%)$ presented a relapsing-remitting course, $68(34.9 \%)$ a secondary progressive course, and 9 patients $(4.6 \%)$ a primary progressive course. Nineteen $(9.7 \%)$ patients were unclassifiable.

The average length of time between the clinical onset and the first relapse (available in only 174 patients) was $34.5 \pm 35.4$ months, with a median of 24 months and range of 1 to 204 months.

Regarding the initial symptom in our sample, the most common was sensory $(60 ; 30.9 \%)$ followed by motor $(36$; $18.6 \%)$, optic neuritis $(34 ; 17.4 \%)$, brainstem $(21 ; 10.8 \%)$, cerebellar $(21,10.8 \%)$, and sphincter disturbance $(6 ; 3.1 \%)$. Seventeen $(8.8 \%)$ had other forms of symptoms at onset.

The scores of Kurtzke's Expanded Disability Status Scale (EDSS) ${ }^{13}$ show a bimodal distribution with a first peak at 2.5 and the second peak at 6.5. The mean score was $3.6 \pm 2.2$, and the median was 3 . In particular, $61.1 \%$ of patients showed either no disability or minimal disability (EDSS 0 to 3.5), 15.9\% showed relatively severe disability (EDSS 4 to 5.5 ), and $23.3 \%$ showed severe disability $(\mathrm{EDSS}>5.5)$.

Incidence. From 1975 to 1994, 170 patients (75 men and 95 women) living in the study area had the clinical onset of the disease. Of these, 149 were classified as CDMS, 3 as LSDMS, and 19 as CPMS. The mean age at onset was $29.8 \pm 9.9$ years (29.7 years for men and 29.7 years for women), ranging from 8 to 59 years; the median age was 28 years.

During the incidence period, the average population was 374,049 (180,257 men and 193,114 women). The average annual onset-adjusted incidence was 2.3 per 100,000 (95\% CI 2.0 to 2.6). Incidence for women was 2.5 per 100,000 (95\% CI 2.0 to 3.0) and for men 2.1 per 100,000 (95\% CI 1.6 to 2.6 ). Table 2 shows average annual incidence rates for 5-year intervals from 1975 to 1994 . The incidence increased from 1.3 during 1975 to 1979 to 3.9 during the last period 1990 to 1994 . Incidence was particularly higher in women than in men during the last period 1990 to 1994 (3.2 for men and 4.5 for women).

Age-specific incidence increased in both sexes in the first groups of age with a peak in the group aged 25 to 34 , 6.3 per 100,000 (5.2/100,000 for men and 7.4/100,000 for women), and showed a steep decline in other age groups. Table 3 and figure 2 show the distribution of age- and sex-specific incidence rates.

Table 2 Average annual incidence of MS in Catania, Italy for 5-year intervals from 1975 to 1994

\begin{tabular}{|c|c|c|c|c|c|c|c|c|c|c|c|c|}
\hline \multirow[b]{2}{*}{ Years } & \multicolumn{4}{|c|}{ Men } & \multicolumn{4}{|c|}{ Women } & \multicolumn{4}{|c|}{ Both sexes } \\
\hline & $\begin{array}{c}\text { No. of } \\
\text { cases }\end{array}$ & Population & $\begin{array}{c}\text { Rate per } \\
100,000\end{array}$ & $95 \%$ CI & $\begin{array}{l}\text { No. of } \\
\text { cases }\end{array}$ & Population & $\begin{array}{c}\text { Rate per } \\
100,000\end{array}$ & $95 \%$ CI & $\begin{array}{l}\text { No. of } \\
\text { cases }\end{array}$ & Population & $\begin{array}{c}\text { Rate per } \\
100,000\end{array}$ & $95 \%$ CI \\
\hline $1975-1979$ & 15 & 194,417 & 1.5 & $0.8-2.5$ & 12 & 205,170 & 1.2 & $0.5-2.1$ & 27 & 399,830 & 1.3 & $0.8-1.9$ \\
\hline 1980-1984 & 14 & 185,644 & 1.5 & $0.8-2.5$ & 20 & 198,304 & 2.0 & $1.2-3.1$ & 34 & 384,524 & 1.8 & $1.2-2.5$ \\
\hline 1975-1994 & 75 & 180,257 & 2.1 & $1.6-2.6$ & 95 & 193,114 & 2.5 & $2.0-3.0$ & 170 & 374,049 & 2.3 & $2.0-2.6$ \\
\hline
\end{tabular}


Table 3 Age- and sex-specific average annual incidence of MS in Catania, Italy

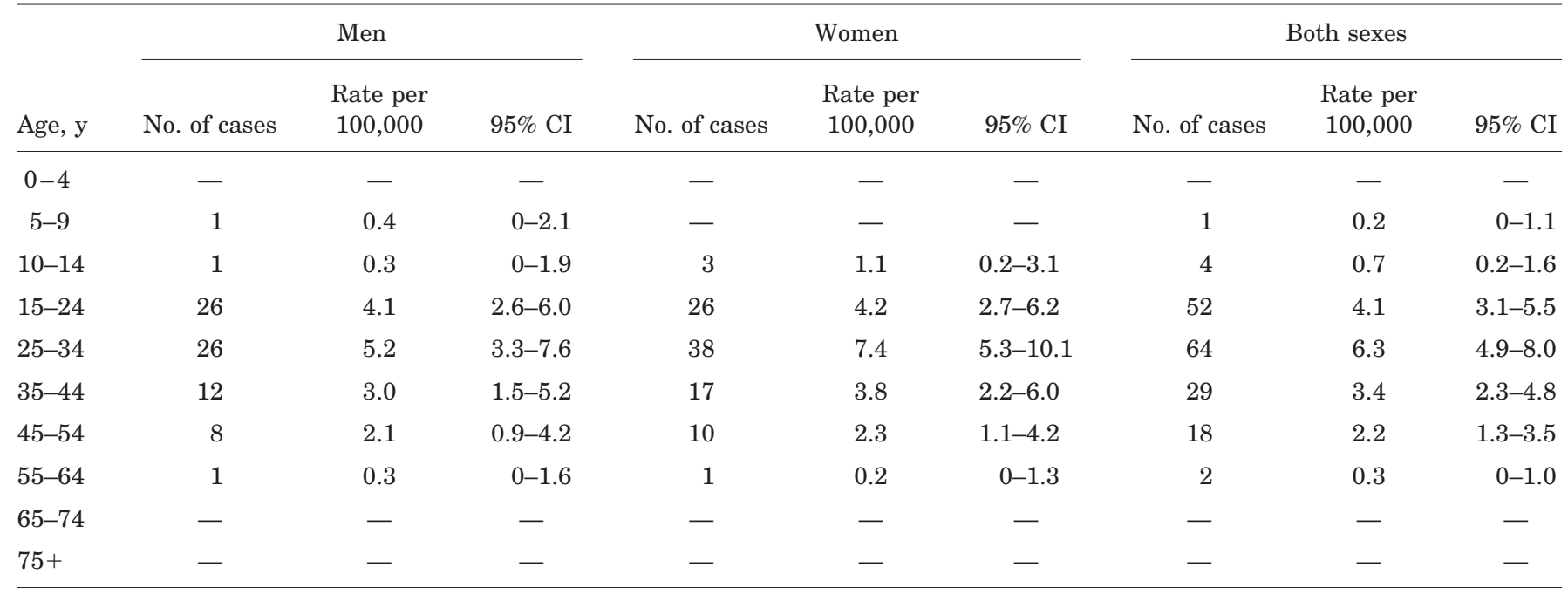

The length of time between the date of clinical onset and the date of the diagnosis shortened considerably during the incidence study period and in particular in the last 5 years. The average was $8.6 \pm 5.6$ years for the first 5 -year period 1975 to $1979,7.7 \pm 4.2$ years during 1980 to $1984,3.5 \pm 3.0$ years during 1985 to 1989 , and $1.9 \pm 2$ years in the last 5-year period 1990 to 1994 .

Discussion. The comparability of prevalence and incidence surveys depends on similarities in the size, structure, and ethnic composition of the population and the diagnostic criteria adopted. The size of populations may be a source of bias. Most of the studies carried out in western Europe have investigated populations of 200,000 to 500,000 inhabitants, which is a desirable working size. Few Mediterranean studies are based on population samples in the same range as contemporary studies in central and northern Europe. ${ }^{1}$ Our study denominator was 333,075 inhabitants for a more precise and comparable estimate of MS frequency.

To allow an international comparison, we used the diagnostic criteria of Poser et al., ${ }^{9}$ which are widely adopted in surveys performed from 1980, considering in our analysis both defined and probable MS.

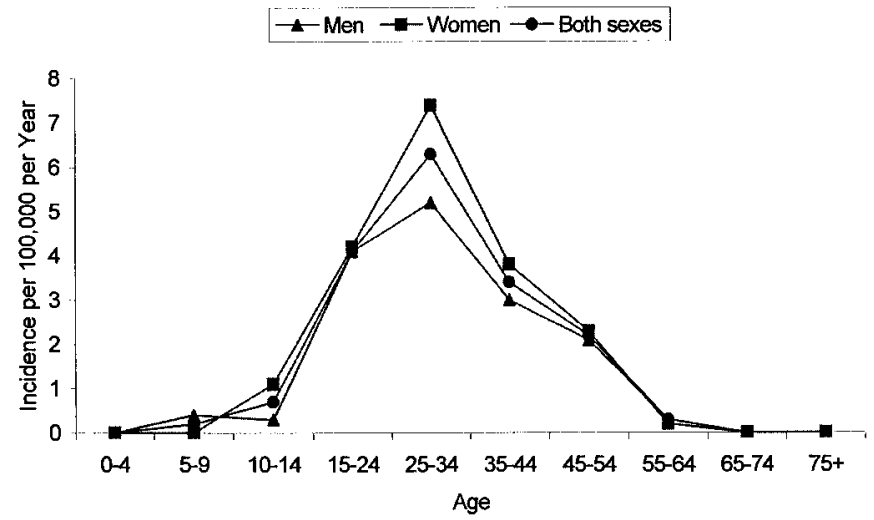

Figure 2. Age- and sex-specific average annual incidence of MS in Catania.
Several studies to determine the frequency of MS have been carried out in Europe from 1980 to date. Prevalence in northern Europe (north of $46^{\circ}$ latitude) is, on average, higher than those reported in the south, showing rates that can be greater than 100 per $100,000 .{ }^{1}$ Rates from southern Europe (between $36^{\circ}$ and $46^{\circ}$ latitude) are on average lower than northern ones, ranging from 26 to 83 per $100,000 .{ }^{1}$ An exception is the study carried out in the Croatian community of Gorski Kotar, where a rate of 124 per 100,000 was reported in $1986 .{ }^{14}$ As regards the frequency of MS in Italy, prevalence ranged from 21.5 per 100,000 in Pescara $(1990)^{2}$ to 143.9 per 100,000 in Sardinia (1991). ${ }^{4}$ Our crude prevalence of 58.5 per 100,000 (95\% CI 50.7 to 67.5 ) is close to those reported in Valle d'Aosta in 1985 (38.4./100,000), ${ }^{15}$ Macerata in 1988 (37.5/100,000), ${ }^{16}$ Ascoli Piceno in $1988(42.8 / 100,000),{ }^{16}$ Ferrara in $1993(69.4 / 100,000),{ }^{3}$ and Reggio Emilia in 1995 (39.44/100,000). ${ }^{17}$

Four studies were carried out in the center and in the west cost of Sicily during 1975 to 1985, showing rates ranging from 32 to 51 cases per $100,000 .{ }^{18-21}$ All these surveys investigated smaller populations (not greater than 60,000 inhabitants) and used different diagnostic criteria. A second survey was carried out in Monreale in 1991, showing a higher rate (72.4/ $100,000)$ than that reported in $1980(43 / 100,000) .^{22}$ In 1989, an epidemiologic survey was carried out in Catania, reporting a prevalence rate of 12 per 100,000 , lower than that of this study. ${ }^{6}$ Several factors could play a role in these difference rates. In 1989, different diagnostic criteria were used, and only patients with a defined diagnosis of MS at the prevalence day were considered. An improvement in MS diagnosis during the last 10 years may be also due to the more common use of sophisticated diagnostic procedures (MRI) and probably to a greater public awareness of this disease.

In our study, the distribution of age- and sexspecific prevalence is similar to that reported in the literature. 
Incidence rates in northern Europe ranged from 0.8 per 100,000 (Hungary) to 7.2 in the United Kingdom. Incidence rates in southern Europe ranged from 1.8 found in Greece (1970 to 1984) to 3.0 in Spain (1986 to 1992). ${ }^{1}$ Higher rates were found in Sardinia (5.1) and Croatia (5.9). ${ }^{14,23}$ As reported, these higher values are probably due to a particular ethnic composition of these populations.

Our average annual onset-adjusted incidence was 2.3 per 100,000 (95\% CI 2.0 to 2.6), which is close to those reported in other surveys (1.59 Reggio Emilia, 2.1 Valle d'Aosta, 2.3 Ferrara).,2,15,17

Considering the average annual incidence rates for 5-year intervals from 1975 to 1994, incidence increased from 1.3 during 1975 to 1979 to 3.9 during 1990 to 1994.

The increased frequency may be caused by a real change in MS risk but could also reflect improvements in case ascertainment and diagnosis. This last hypothesis is also supported by the fact that the average length of time between the onset and the diagnosis decreased during the study period, from 8.6 during 1975 to 1980 to 1.9 in the last 5-year interval, 1990 to 1995.

\section{Acknowledgment}

The authors thank the staff of the Multiple Sclerosis Center of the University of Catania for their contributions. They also thank all of the people and the institutions that helped in this study, and particularly their colleagues in the Department of Neurology of the Garibaldi Hospital and the local Italian MS Association.

\section{References}

1. Rosati G. Descriptive epidemiology of multiple sclerosis in Europe in 1980s: a critical overview. Ann Neurol 1994; 36(suppl 2):S164-S174.

2. Malatesta G, Gabriele A, Macor S, Giampietro A, Fulgente T, Gambi D. Diffusion of multiple sclerosis in two Italian provinces, Chieti-Pescara. Ital J Neurol Sci 1991;12(suppl 5):83. Abstract.

3. Granieri E, Malagù S, Casetta I, et al. Multiple sclerosis in Italy. A reappraisal of incidence and prevalence in Ferrara. Arch Neurol 1996;53:793-798.

4. Casetta I, Granieri E, Marchi D, et al. An epidemiological study of multiple sclerosis in central Sardinia, Italy. Acta Neurol Scand 1998;98:391-394.

5. Granieri E, Casetta I, Tola MR. Epidemiology of multiple sclerosis in Italy and southern Europe. Acta Neurol Scand 1995; 91(suppl 161):60-70.
6. Grasso AA, Reggio A, Marano P, et al. Epidemiological survey of multiple sclerosis in Catania city. Ital J Neurol Sci 1992;13: 301-309.

7. Istituto Centrale di Statistica. $13^{\circ}$ Censimento generale della popolazione. October 20, 1991.

8. Epi Info [computer program]. Version 6. Atlanta, GA: Centers for Disease Control \& Prevention, 1994.

9. Poser CM, Paty DW, Scheinberg L, et al. New diagnostic criteria for multiple sclerosis: guidelines for research protocols. Ann Neurol 1983;13:227-231.

10. Poser CM. Onset symptoms of multiple sclerosis. J Neurol Neurosurg Psychiatry 1995;58:253-254.

11. Muir C, Waterhouse J, Mack T, Powell J, Whelan S, eds. Cancer incidence in five continents. Lyon, France: IARC (WHO), 1987.

12. Schoenberg BS. Calculating confidence intervals for rates and ratios: simplified method utilizing tabular values based in the Poisson distribution. Neuroepidemiology 1983;2:257-265.

13. Kurtzke JF. Rating neurologic impairment in multiple sclerosis: an expanded disability status scale (EDSS). Neurology 1983;33:1444-1452.

14. Sepcic J, Materljan E, Antonelli L, et al. Multiple sclerosis cluster in Gorski Kotar, Croatia, Yugoslavia. In: Battaglia MA, ed. Multiple sclerosis research. Amsterdam, the Netherlands: Elsevier Science, 1989:165-169.

15. Sironi L, Mamoli A, D’Alessandro G, Camerlingo M, Bottacchi E. Frequency of multiple sclerosis in Valle d'Aosta 1971-1985. Neuroepidemiology 1991;10:66-69.

16. Angeleri F, Bollettini G, Brizioli E, Giuliani G, Scarpino O. A prevalence study of multiple sclerosis in Regione Marche Italy. In: Battaglia MA, Crimi G, eds. An update on multiple sclerosis. Bologna, Italy: Monduzzi, 1989:209-212.

17. Guidetti D, Cavalletti S, Merelli E, et al. Epidemiological survey of multiple sclerosis in the provinces of Reggio Emilia and Modena, Italy. Neuroepidemiology 1995;14:7-13.

18. Dean G, Grimaldi G, Kelly R, Karhausen L. Multiple sclerosis in southern Europe. I: prevalence in Sicily in 1975. J Epidemiol Community Health 1979;33:107-110.

19. Savettieri G, Daricello B, Giordano D, Karhausen L, Dean G. Prevalence of multiple sclerosis in Sicily. I. Monreale city. J Epidemiol Community Health 1981;35:114-117.

20. Dean G, Savettieri G, Giordano D, et al. Prevalence of multiple sclerosis in Sicily. II: Agrigento city. J Epidemiol Community Health 1981;35:118-122.

21. Savettieri G, Elian M, Giordano D, Grimaldi G, Ventura A, Dean G. A further study on the prevalence of multiple sclerosis in Sicily: Caltanissetta city. Acta Neurol Scand 1986;73: 71-75.

22. Savettieri G, Salemi G, Ragonese P, Aridon P, Scola G, Randisi G. Prevalence and incidence of multiple sclerosis in the city of Monreale, Italy. J Neurol 1998;245:40-43.

23. Rosati G, Aiello I, Pirastru MI, et al. Epidemiology of multiple sclerosis in Northwestern Sardinia: further evidence for higher frequency in Sardinians compared to other Italians. Neuroepidemiology 1996;15:10-19. 


\title{
Neurology
}

\author{
Prevalence and incidence of multiple sclerosis in Catania, Sicily \\ A. Nicoletti, M.L. Lo Bartolo, S. Lo Fermo, et al. \\ Neurology 2001;56;62-66 \\ DOI 10.1212/WNL.56.1.62
}

This information is current as of January 9, 2001

\section{Updated Information \& Services}

References

Citations

Subspecialty Collections

Permissions \& Licensing

Reprints including high resolution figures, can be found at: http://n.neurology.org/content/56/1/62.full

This article cites 14 articles, 4 of which you can access for free at: http://n.neurology.org/content/56/1/62.full\#ref-list-1

This article has been cited by 5 HighWire-hosted articles: http://n.neurology.org/content/56/1/62.full\#\#otherarticles

This article, along with others on similar topics, appears in the following collection(s):

All Demyelinating disease (CNS)

http://n.neurology.org/cgi/collection/all_demyelinating_disease_cns All epidemiology

http://n.neurology.org/cgi/collection/all_epidemiology

Incidence studies

http://n.neurology.org/cgi/collection/incidence_studies Multiple sclerosis

http://n.neurology.org/cgi/collection/multiple_sclerosis

Prevalence studies

http://n.neurology.org/cgi/collection/prevalence_studies

Information about reproducing this article in parts (figures,tables) or in its entirety can be found online at:

http://www.neurology.org/about/about_the_journal\#permissions

Information about ordering reprints can be found online:

http://n.neurology.org/subscribers/advertise

Neurology ${ }^{\circledR}$ is the official journal of the American Academy of Neurology. Published continuously since 1951, it is now a weekly with 48 issues per year. Copyright . All rights reserved. Print ISSN: 0028-3878. Online ISSN: 1526-632X.

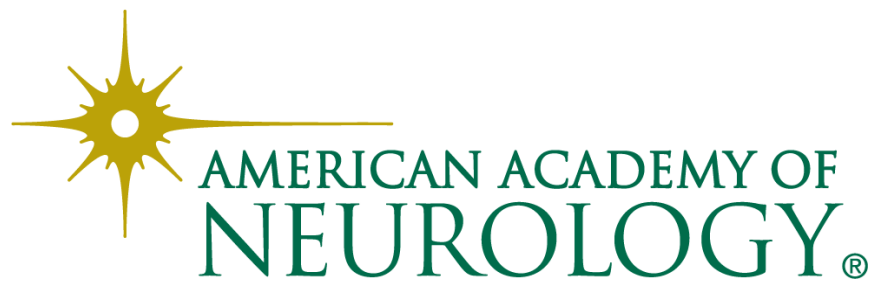

